\title{
A National Network of Biological-Agricultural Libraries
}

\begin{abstract}
Efforts to gain systematic control of the entire range of biological and agricultural literature are reviewed. In view of the need manifest therein, an efficient network of biological-agricultural libraries is being developed to serve the science communities in those fields. MEDLARS is already operational, and NAL is now developing a network in the bio-agricultural fields. Problems in the way of its satisfactory establishment are discussed, and the elements of such a system are enumerated.
\end{abstract}

\section{INTRODUCTION}

$\mathrm{T}$ HE 1966 CONFERENCE of the American Library Association sat at the center of two concentric circles. The smaller or inner circle, covering greater New York, includes one of the most significant concentrations of books and libraries of all times-at least 30 million volumes. The New York public library, the Columbia University library, the ten to twenty other significant academic library collections plus more than one thousand outstanding special libraries provide a scope and depth of information that is in many ways incomparable. Our second circle, with a radius of 250 miles, encompasses the Harvard-Cambridge-New Haven area in the north and the Washington, D. C. metropolitan area library complex in the south. Within this larger area the number of volumes has doubled to more than sixty million and the range and depth of subjects have measurably increased. Sitting in the center of this library affluence we might assume that all is well in the scholarly library field

Mr. Mohrhardt is Director of the $\mathrm{Na}$ tional Agricultural Library and Mrs. Oliveri is Assistant Director for Coordination Services. This paper was read to the Agriculture and Biological Sciences Subsection of ACRL in New York City on July 14, 1966. and that practically any research worker's needs can be met in this relatively confined geographical area. The director of the Columbia University library, Richard Logsdon, viewed with pride the strength of these collections in the greater New York area, and reported in candor last year:

But lest you be lulled into believing that all is well in the library world, let me now give the specialist reader's view. With all of these resources, libraries are still falling short of meeting the full demands of readers, in these days of upgraded elementary and secondary curricula, new specializations at the college and university level, and the incredible expansion of research, particularly in the sciences. At Columbia, for example, I cannot think of a single field in which members of the faculty could not find us lacking in significant source material. ${ }^{1}$

We who work in the larger circle with a sixty to seventy-five million volume total recognized the fact that many of the needs of research workers, scholars and students are unmet by all of these collections.

As the horizons of interest of our scholars and students increase, and as the production of papers and publica-

\footnotetext{
${ }^{1}$ Richard H. Logsdon, "The Vast Resources of New York City and the Developments Which Will Occur in the Next Decade" (A privately printed address of April 15, 1965), p. 14.
} 
tions double in output with predicted regularity, most libraries have recognized their individual inability to meet even a share of their users' requirements.

We will have to redouble our efforts and rechallenge our ingenuity and imagination to maintain even our present levels of service. There are many nights when we go home from our libraries wondering if there are any boundaries to the quest for information. William $\mathrm{O}$. Baker, one of our greatest scientists and research directors, says, "Unlike material consumption-of food, clothing, housing, even, perhaps, of automobiles-there is probably no limit to human needs for knowledge."

Many of us today are aware of the fact that new paths must be opened and new approaches developed in the field of librarianship. Librarians for several decades have been aware of the fact that the handling and servicing of publications has become a problem beyond the competence of conventional systems. It has only been in the last decade however, that scientists and research workers recognized these difficulties.

Librarians and scientists also know that individual efforts are no longer sufficient, and that regional and national programs are needed to handle successfully the requirements of research workers, students, and others.

\section{Biology and Agriculture}

The American Institute of Biological Sciences established in 1960 the Biological Sciences Communication Project to "study, define, and improve the flow of fundamental and applied biological information from the scientist producer to the scientist consumer." ${ }^{3}$

The project's proposals, particularly as they applied to the national scene, were

\footnotetext{
${ }^{2}$ William O. Baker, "Communication Science-Today and Tomorrow," in Science and Society: A Symposium (Rochester, N.Y.: Xerox Corp., 1965), p. 100.

AIBS. Biological Sciences Communication Project. Communique, 1-61 (June 1961), 2.
}

probably too advanced and comprehen. sive for the early 1960 's. Unfortunately, they were not put into operation. The project is now a part of George Washington University and still serves as an effective center for research, education, and special studies in the biological sciences communication field.

Looking for a broader base of biological representation, a new effort to inventory, evaluate, and systematize the national handling of biological information was initiated in a conference on communications for biology held at Cherry Hill, New Jersey, November 1965. The conference participants were carefully selected to cover comprehensively the whole field of biology, from the central core of basic, discipline-oriented biology to the mission-oriented and more applied fields of agriculture and medicine. Among the recommendations made at the meeting that apply particularly to librarains are the following.

IX. That biological vocabularies or thesauri including definitions and hierarchical structures be developed under the joint efforts of scientists, science information specialists and societies for use in indexing and handling of biological publications and communication....

$\mathrm{X}$. That it be the responsibility of the federal government to insure acquisition and reasonable availability in the United States of all significant publications in biology from any part of the world.

A. Reasonable availability includes prompt cataloging of publications, (2) an express announcement in English for all titles of publications collected, (3) plus selective dissemination of this title information. All services should be provided by utilizing existing organizations both public and private. The prime objective is to facilitate rapid transmission of copies of original documents to the individual through a local institution at minimal cost.

B. A Council at the national level should be urged to assume over-all responsibil- 
ity for implementation of this program in cooperation with the appropriate biological organizations and societies. Specific delegation of broad subject areas should be made, utilizing as document sources the National Library of Medicine and the National Agricultural Library and recognizing outstanding specialized collections that have been developed at local institutions, such as exist in mammalogy, ichthyology, mycology, bryology, and photosynthesis.

XI. That library services to the biologist at the local level must be immediately strengthened and local libraries must be brought into the national planning at an early stage so that they can provide better services.

That academic and other research institutions recognize the need for adequately supported library service in developing all research programs, and that federal assistance for research include provision for libraries. ${ }^{4}$

In addition it was proposed that a network of libraries, data centers, documentation centers, and information centers be implemented to carry out the conference recommendations and meet the needs of biologists for information.

It is to librarians that the biologists have directed their request for aid. We are the specialists who are expected to provide solutions.

\section{LIBRARY NETWORKS-A NATIONAL ResponsibILITY}

Today we can readily recognize the problems, identify broad needs, and subscribe to the idea of a national bio-agricultural network. The difficult problems arise in designing, organizing, and operating an efficient network of information services. Since the organization of the American Library Association almost a hundred years ago, libraries in this country have been utilizing most of the fundamental elements necessary for

4 Conference on Communications for Biology. Cherry Hill, N.J.: Nov. 22-23, 1965 . Report. pp. 7-8. an effective network. We have a national interlibrary loan system, standardization of catalog cards through the Library of Congress, codes and rules for subject headings, storage centers, and arrangements for division of collecting responsibility in some subject fields. Yet each of these elements now in operation contains exceptions, limitations, and deficiencies that can be improved only by broader planning and better structuring.

Every current major study of libraries, information services, and communication has pointed to the federal government as a major factor in stimulating, supporting, and organizing networks for these services. As Adlai E. Stevenson pointed out in a discussion of science and technology:

Electricity had been harnessed fifty years in the United States before it was put to work on the farm. It was political will that put it there.

It was political initiative which built TVA, the Grand Coulee Dam, the super highways, years after we knew how.

It was a political trigger which started the huge programs of research in science in universities and private industry. ${ }^{5}$

Let us tap this political potential to serve us in network development!

J. C. R. Licklider, who has recently studied library potentials, also directs us toward federal interests.

What has the federal government's apparatus for scientific and technical information to do with "problems in information retrieval"? Three things: First, it has problems, large and deep, which it is mounting a vigorous effort to solve. Second, it offers to scientists and engineers a great and valuable informational resource that is much less well known and well understood than it should be among some of the people who could best use its help and who could best help it. And, third, the integration of national resources in the informa-

5Adlai Stevenson, "Science and Technology in the Political Arena" in Science and Society: A Symposium (Rochester, N.Y.: Xerox Corp., 1965), p. 7. 
tion field must involve both the federal resources and the resources outside the government. . . . ${ }^{6}$

In private conversation with me he has pointed out that-

The MEDLARS project at the National Library of Medicine, the network of statebased information centers to be established under the State Technical Services Act of 1965, the Atomic Energy Commission and National Aeronautics and Space Administration computer-based abstracting and indexing services, the new computer-based chemical information system of the Chemical Abstracts Service, and the numerous information evaluation and analysis centers are all examples of large-scale information transfer experiments which will lead to improved systems design and integration.

What have we established thus far? First, that individual libraries and even small groups of libraries are no longer adequate for the general needs of research workers, scientists, and students. Second, biologists and agriculturalists have now directly challenged us to find the techniques and methods to give them ready access to the totality of world information in biology. Third, within the tradition of American library experience we have the basic elements for a national network or system. Fourth, the role of the federal government in library support and stimulation has been well established during the past decade. Fifth, many government agencies now have specialized networks providing information which can be fed into the total biological-agricultural network. Where do we go from here?

The National Library of Medicine, through its MEDLARS project and other activities, already has in operation an experimental network for the broad health-centered fields. The National Agricultural Library is now developing

- J. C. R. Licklider, "Some Problems in Information Retrieval" (A paper prepared for presentation August 27, 1965 at the Western Computer Conference in San Francisco). the base for a broad nationwide bioagricultural library network. Before outlining the steps already taken by the National Agricultural Library it is necessary to reemphasize certain guidelines that must be accepted by all of us if we are to progress rapidly in a shared, cooperative, effective national network.

Network Planning and Organization. A functioning national network for biological-agricultural information will require: (1) formalizing of agreements and arrangements between the participating libraries; (2) increased sharing of responsibilities; (3) increased cooperation in acquisitions; (4) standardization of procedures; (5) re-education of users.

Much of what we are referring to here has also been discussed in library circles under the rubric "compatibility."

\section{CompatibILITY}

Librarians are individualists. For almost one hundred years we have utilized various types of standardization and classification: subject headings, catalog card format, etc., yet each library introduces modifications and elaborations for its own particular needs. A national network for biology and agriculture will require us to review these individual modifications and determine which are necessary and which are merely traditional and perhaps outmoded. The standardization of our library activities leading toward a high degree of compatibility will cause the first feeling of uneasiness on the part of cooperating librarians. We object to being cogs in a machine or merely purveyors of packaged objects, but these objections are not necessary.

In a recent talk, William Welsh of the Library of Congress reminded us that-

Although standardization of certain elements of catalog card data has been realized since the advent of the LC printed card in 1899, maximum benefits to be derived from such standardization have not yet been achieved. 
Despite evidence of increasing use of LC cards ... there is also present more than a strong suspicion that many, if not most, libraries adapt the LC card to render it compatible with their system.

The era of automation creates the opportunity to re-examine the present bibliographical record and to produce a machine output of that record which will serve the needs for which libraries exist and hopefully, thereby, eliminate or markedly reduce the inefficiencies implicit in "adaptation."7

The confrontation between librarians and computers is taking place today and the relationship between the computer systems and the librarians at the Library of Congress and the National Library of Medicine fail to show any impairment to library service through computer usage. The National Library of Medicine, with a computerized cataloging system now in operation, reports that both the users and librarians are well satisfied with the new services.

For the purposes of this paper and to eliminate a factor that can overshadow the fundamentals of network development, we will not involve ourselves with the problems of computer usage and mechanization of the system. These are tools that will be used as the system develops. At this time they are not the basic elements of the system.

\section{Elements of the System}

If the Agriculture and Biological Sciences Subsection of ACRL should decide to assume responsibility for aiding in the development of a national bioagricultural network, it will immediately be necessary to define the scope of the following elements:

1. A national plan. This would involve both immediate and long range activities.

2. Establishment of a responsible agent or center for the system.

"William J. Welsh, "Compatibility of Systems" (A paper presented at the Conference on Data Processing in University Libraries). Drexel Institute, 1965.
3. Establishment of a referral apparatus.

4. Identification of financial support.

5. Delegation of responsibilities. There would be a need to formalize acquisitions policies, cataloging, services, and subject specialization.

Those who have studied the general needs and bases for library networks have stressed the importance of exploring new fields of service in addition to the conventional handling of books, journals, other published information and bibliographies. Since the local librarian under a standardized network system would be relieved of many routine concerns about limitations of acquisitions, cataloging, and the immediate availability of a wide range of subject information, new oportunities will be presented at the local and regional level for librarians to develop challenging projects. These could include indexing in depth for special fields, selective abstracting, preparation of state of the art or review papers, and the provision of more and better personal service to the clientele. In addition, opportunities would be open for libraries to handle a broader range of information including much unpublished information such as data, laboratory notes, unpublished symposia papers, etc.

\section{NAL Network Plans}

The National Agricultural Library's plan for a network is being developed in three phases. First, coordination within the Department of Agriculture. Second, formalized cooperation with agricultural universities and experiment stations. Finally, cooperative arrangements with all other biological-agricultural information units.

The library's coordinator of scientific and technical information works with counterparts in each agency of USDA. All department agencies make a preclearance check before preparing extensive bibliographies and translations and 
report to the library any studies, surveys, or projects involving vocabularies or research and development in scientific communication and documentation.

Agricultural Vocabulary Project. A basic authoritative agricultural/biological vocabulary for information storage and retrieval of published literature and unpublished research is well under way. This will serve the entire Department of Agriculture, the land-grant universities as well as other government-wide vocabularies which have interests in these fields. In November 1965 our first agricultural-biological subject category list was published. The list consists of fifteen major fields which are further divided into ninety-eight groups similar in structure to the COSATI subject category list. This framework provides subject approaches for both published literature and unpublished research reports. Early this year we were fortunate in securing the cooperation of four land-grant insitutions (Pennsylvania State University, Purdue University, Massachusetts Institute of Technology, and the University of Wyoming), each of which provided the services of a librarian to assist us in developing the basic vocabulary. Our next steps are evaluation and building the reference structure.

Scientists in each of the major disciplines covered by the vocabulary will now evaluate the terms and provide us with an approved basic list. At the same time we will be developing specialized lists such as taxonomic names and names of chemical substances. The basic vocabulary should be issued by June 1967 .

Library of Congress Classification Scheme. Publication of the Dictionary Catalog of the National Agricultural Library, 1862-1965, made it possible for the library to change the classification scheme it had been using for the past one hundred years.

Correspondence with the land-grant institutions showed a trend in agricul- tural libraries toward using the Library of Congress classification scheme. Therefore, we changed to the LC schedules in January 1966. Now two of the national libraries are using the same subject classification.

Future Plans. We have now reached the point where we are making more extensive contacts with universities, experiment stations, and industrial installations in furthering the cordination of agricultural information.

We recently sent a questionnaire to all libraries of land-grant universities and experiment stations to gather preliminary data for developing an agricultural network. (1) We are trying to identify the state services which are provided to federal employees headquartered within the state. For example-are direct routing, lending, reference, or bibliographic services being provided USDA employees? (2) We want to find out which libraries will be willing to assume archival and national service responsibilities for state and county bureau publications, and for state, county, and municipal publications produced within their state. (3) We are also trying to identify various subjects or geographic areas for which libraries will assume similar responsibilities.

An additional activity essential to a network is an inventory of agricultural information resources throughout the country. Over three hundred and forty have been identified within the Department of Agriculture alone. Our attention is now directed to other governmental, academic, industrial, and historical institutions. This provides potential components of the network bases for referral activities. We hope to eliminate unnecessary duplication, to expand essential areas, and to tailor our future activities in accordance with recommendations received.

Decentralization Concept. We have two formal agreements already executed. 
The University of California at Davis has assumed national responsibility for agricultural machinery catalog acquisition and servicing. The Tennessee Valley Authority has assumed national collection and servicing of publications on fertilizers.

The Davis agreement represents our first cooperative endeavor, and makes available the most comprehensive collection in the United States of agricultural machinery catalogs and related materials. The TVA agreement was a logical follow-up to the Department of Agriculture's termination of most fertilizer research and the TVA's national responsibility and capability for performing such research activities.

Both agreements provide for assumption of national responsibility for acquiring and disseminating pertinent information. They will provide national bibliographic, reference, and interlibrary loan services.

\section{OTHER ACtivities}

The ultimate aim of the National Agricultural Library is to make possible the utilization of tapes provided from its mechanized system, and an interchange of tapes within the bio-agricultural network. The library's system is progressing on a phased basis.

The monthly and annual author indexes of the Bibliography of Agriculture were automated in August 1964. The programing and testing of the subject index system is underway, and will provide for the first time monthly subject indexes to the Bibliography of Agriculture in addition to the annual cumulation. Automation of the citations themselves, scheduled for 1969, will permit the preparation of periodic bibliographies on specialized subjects, selective dissemination of pertinent scientific information, and responses to demand searches.

The Pesticides Information Center, which is currently issuing a computerproduced permuted title index, will change over to the new computer-based system being developed by the Datatrol Corporation. The new Pesticides Documentation Center will include a retrieval system for special bibliographies and demand searches, with selective dissemination if warranted.

Eventually we hope to have on file and to service a user profile for any bioagricultural institution in the country which desires selective dissemination to be made from the total mechanized system.

\section{Discussion}

Several questions immediately arise as a result of this discussion and the summary of our program. First, we probably will have to determine who would be the initial participants in such a system. For practical purposes it would probably be best to limit the initial participants to land-grant universities and other major agricultural libraries, or to mount a smaller more varied pilot project.

Next a determination will have to be made concerning the extent of coverage and service. Since the network is primarily a practical device, a priority should be established for the types of materials to be handled in the system. For example how would we arrange priorities for the following:

1. Would it be best to begin the network for service on publications most used?

2. Or would it be preferable to specialize on those least used?

3. How about the publications that are hardest to identify and acquire? (For example, symposia and conference papers.)

4. What is the interest in publications that are hardest to handle because of their size and other factors?

5. Report literature? 
6. Theses?

7. Newspapers?

8. Basic and comprehensive historical collections in subject fields?

9. Rare books?

These and others must be examined before we establish priorities.

A network arrangement can give valuable assistance in solving our serious storage problems. As long as we work independently or with highly informal and indefinite exchange and cooperative programs, each library is faced with a mounting problem of storage of publications. Under an effective national network system, however, we never need to concern ourselves, since we have a continuing certainty that someone holds responsibility and will have available for us the publications whenever they are needed.

\section{INTERNATIONAL}

As our circle widens we must look toward a truly international network. The National Library of Medicine is already furnishing its tapes to special libraries in various European countries and is exploring the possibility of contracting for bibliographic and abstracting aid abroad.

We in agriculture are greatly dependent upon services from other countries in bibliographic and abstracting fields. The Commonwealth Agricultural Bureaux furnishes the widest abstracting in agriculture. We also utilize abstracting and indexing services issued by the USSR, the Netherlands, France, Ger- many, and Japan. The nucleii for an eventual international system will be strong national agricultural-biological libraries, or in some instances regional organizations set up to provide expanded library services. In the agricultural field highly effective regional groups are now operating in Latin America, the Scandinavian countries, the "Socialist countries," and in Great Britain. Other elements in the eventual network will be subject-oriented centers such as the International Rice Research Institute in the Philippines, which is already serving as an international center.

Leadership for the establishment of such an international system can be expected from the International Association of Agricultural Librarians and Documentalists, the Food and Agriculture Organization, and our own National Agricultural Library.

The World Congress of Agricultural Librarians and Documentalists, held in Washington last year with representatives from thirty-five countries, recorded its urgent wish to take the first steps toward an international bio-agricultural network. Each country is as eager to share its intellectual resources as it is to call upon those of other countries. We have a need, we have an interest, and we have an enthusiasm on the part of librarians and those they serve in every part of the world. The National Agricultural Library is ready to move today in the establishment of the first phase of both the national and international networks.

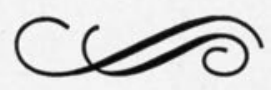

